\title{
Epidemiology and Therapeutics Aspects of Pressure Ulcers in Two Sub-Sahara African University Teaching Hospitals
}

\author{
Guifo Marc Leroy ${ }^{1,2}$, Essomba Arthur Georges ${ }^{1,2}$, Djiodoung Zoko Serge ${ }^{3}$, Bwelle Motto \\ Georges $^{1,4}$, Vuagnat Hubert ${ }^{5}$, Sosso Maurice Aurelien ${ }^{1,6}$ \\ ${ }^{1}$ Faculty of Medicine and Biomedical Sciences University of Yaoundé 1, Department of Surgery and \\ Anesthesiology; Yaoundé \\ ${ }^{2}$ University Teaching Hospital (CHU) of Yaoundé \\ ${ }^{3}$ Institut Supérieur de Technologie Médicale; Yaoundé \\ ${ }^{4}$ Hôpital central de Yaoundé (HCY) ; Yaoundé \\ ${ }^{5}$ Hôpital Universitaire de Genève (HUG); Geneva \\ ${ }^{6}$ Pro-chancellor, University of Yaoundé1
}

*Corresponding Author: Guifo Marc Leroy, PO box 34699 Yaoundé, Cameroon, E-mail: mlguifo@yahoo.com

\begin{abstract}
Background: Pressure ulcers are frequent complications of bedridden patients. They may be responsible of prolong hospital stay and human resource consumption. We aimed to determine the cumulative incidence of pressure ulcers, investigate external factors, established the interest of surgery in the management of pressure ulcers in our resource-constraint environment
\end{abstract}

Material and Method: In this prospective cohort study, all consenting consecutive patients admitted in some units in two tertiary centers in Yaoundé; Yaoundé University Teaching Hospital (CHU) and Yaoundé Central Hospital (HCY) were enrolled. Over a three-month period, patients at risk (Braden score <16) were regularly examined every 3 days till hospital discharge. Patients with pre-existing pressure ulcers or less than three days hospital stay were excluded. We studied socio-demographic parameters, co-morbidities and findings of clinical examinations.

Results: We enrolled a total of 946 patients; 426 from CHU Yaoundé and 520 from HCY. There were 385 patients at risk of pressure ulcers. The cumulative incidence of pressure ulcers was $20 \%$ in general and $50 \%$ in the population at risk. Prevalent pressure ulcers stages were stage 2 (57.4\%), stage one (30.9\%), stage 3 and $4(\approx 10 \%)$. Surgical management was done in one case of sacral pressure sore out of 11 admitted in surgery at $\mathrm{CHU}$.

Conclusion: There is a considerable prevalence of pressure ulcer in our tertiary hospitals. Few patients are eligible for surgery but their management outcome can be improved by better nutrition, nursing and negative pressure wound therapy.

Keywords: Pressure ulcer, incidence, Braden score, surgical management.

Abbreviations: $C H U$ : Yaoundé University Hospital Center, HCY: Hôpital Central de Yaoundé

\section{INTRODUCTION}

Pressure ulcer is a localized injury to the skin and/or underlying tissues, usually over a bony prominence as a result of pressure or pressure in combination with shear and/or friction [1]. Its prevalence is estimated at $3-20 \%$ in Western countries and $6 \%$ in a neighborhood hospitals of Nigeria [2][3]. These pressure ulcers can be classify according to the degree of injury to skin and underlying tissue into 4 stages; from stage

ARC Journal of Surgery one with only nonblanchable erythema to stage 4 that represent full thickness tissue loss with exposed bone, tendon or muscle. There are some unstageable ulcer when the true deep of the ulcer cannot be determined [1]. Till date, the burden of pressure ulcer on our health care system remains subjective due to scare data from Cameroonian studies. Many factors interact in synergy to potentiate its occurrence and severity. These factors are generally classified as extrinsic and intrinsic [4][5]. With the huge shortage in 
specific equipment like appropriate bed and mattress, insufficient human resources to apply the current preventive recommendations for pressure redistribution, we hypothesized that these external and modifiable risk factors could be optimize to address the problem. We therefore carried out a study to determine the magnitude of the pressure ulcers through its cumulative incidence, as well as to investigate influence of different co-morbidities and to determine the interest of surgery in the management of pressure ulcers in our resource-constraint environment

\section{Materials AND Methods}

In this prospective cohort study we enrolled all consenting consecutive patients at risk of developing pressure ulcers, assessed by a Braden risk assessment score less than 16 at two tertiary centers in Yaoundé; the University Hospital Center of Yaoundé (CHU) and Yaoundé Central Hospital, Cameroon [6][7]. We also enrolled all patients that presented a pressure ulcer of any stage during their stay in the hospital regardless of the assessed Braden score. Patients with preexisting pressure ulcers at hospital admission and those with less than 3 days of hospitalization were excluded from this cohort. In addition, we evaluated the patients in CHU for the possibility of surgical management. Eligibility criteria for surgical management were young patients with stage 3 and 4 pressure ulcers without mobility impairment, patients with stage 3 or 4 ulcers and associated comorbidities (coma, stroke, chronic illnesses) that could not heal spontaneously after 6 weeks according to the definition of chronic wounds, and patients with lower limb paralysis but who psychologically accept their conditions and had support from their families or social networks [8]. We used a structured questionnaire to study demographic characteristics and findings of clinical examinations of participants. All patients were seen at hospital admission for risk assessment through Braden score (Table:1) and were then followed-up every 3 days if they had a score of less than 16 till their discharge from the hospital. Data were analyzed simply with descriptive statistics as percentage, mean. The study was approved by the Institutional Review Board of the Faculty of Medicine of the Higher Institute of Medical Technologies, Yaoundé, Cameroon. Administrative authorizations were equally obtained from the administration of both hospitals involved prior to the beginning of the study.

Table1. Braden scale for predicting Pressure sore risk

\begin{tabular}{|c|c|c|c|c|}
\hline \multicolumn{5}{|c|}{ Severe risk: total score $\leq 9$, High risk $10-12$, Moderate Risk $13-14$, Mild risk $15-18$, max $=23$} \\
\hline Risk factor & \multicolumn{4}{|l|}{ Score/Description } \\
\hline $\begin{array}{l}\text { Sensory } \\
\text { Perception } \\
\end{array}$ & $1=$ completely limited & $2=$ very limited & $\begin{array}{l}3=\text { Slightly } \\
\text { limited }\end{array}$ & $4=$ No limitation \\
\hline Moisture & $1=$ constantly moist & $2=$ often moist & $\begin{array}{l}3=\text { occasionally } \\
\text { moist }\end{array}$ & $4=$ rarely moist \\
\hline Activity & $\begin{array}{l}1=\text { BEDFAST } \\
\text { confined to bed }\end{array}$ & $\begin{array}{l}2=\text { CHAIRFAST } \\
\text { ability to walk } \\
\text { severely limited } \\
\text { and/or must be } \\
\text { assisted into chair }\end{array}$ & $\begin{array}{l}3 \quad=\quad \text { Walks } \\
\text { occasionally }\end{array}$ & $\begin{array}{l}4=\text { Walks frequently; } \\
\text { outside the room at } \\
\text { least twice a day }\end{array}$ \\
\hline Mobility & $\begin{array}{l}1 \quad=\quad \text { completely } \\
\text { Immobile }\end{array}$ & 2 = Very limited & $\begin{array}{ll}3= & \text { Slightly } \\
\text { limited } & \end{array}$ & $4=$ No limitation \\
\hline Nutrition & $\begin{array}{l}1=\text { Very poor; never } \\
\text { eat a complete meal }\end{array}$ & $\begin{array}{l}2=\text { Probably } \\
\text { inadequate, rarely } \\
\text { eat a complete meal }\end{array}$ & $\begin{array}{l}3=\text { Adequate Eats } \\
\text { over half of most } \\
\text { meals }\end{array}$ & $\begin{array}{l}4=\text { Excellent; Eats } \\
\text { most of every meal }\end{array}$ \\
\hline $\begin{array}{l}\text { Friction and } \\
\text { Shear }\end{array}$ & $\begin{array}{l}1=\text { requires moderate } \\
\text { to maximum assistance } \\
\text { in moving }\end{array}$ & $\begin{array}{l}2=\text { Move feebly or } \\
\text { requires minimum } \\
\text { assistance }\end{array}$ & $\begin{array}{l}3=\text { Moves in Bed } \\
\text { and in chair } \\
\text { independently } \\
\text { and has sufficient } \\
\text { muscle strength }\end{array}$ & \\
\hline
\end{tabular}

\section{RESULTS}

We enrolled a total of 946 patients during the 3month study period from April 2016 to June; 426 from University Hospital Center of Yaoundé (CHU) and 520 from Yaoundé Central Hospital (HCY). According to the Braden assessment of risk score, 385 patients were at risk and 193 developed pressure ulcer giving a cumulative incidence of $20 \%$. The mean age of patients with pressure sore was 53.5 years with extremes of 4 
to 90 years. Amongst the patients with pressure sores, 102 were males and 91 were females.

Our patients were sort using different recognize risk factors either due to the underlying diseases or condition or to the interaction with the hospital system through some extrinsic factors. In CHU the three units that were part of the study was Intensive care unit with 71 patients and 35 cases of pressure ulcer $(26.8 \%)$, internal medicine units with 231 patients and 45 cases (19.5\%), Surgical unit with 124 patients and 11 cases (8\%); In Yaoundé Central Hospital the investigation was done in the Cardiology 168 patients with 41 cases (24\%), Neurology79 patients with 23 cases (29\%), Neurosurgery 139 patients with 39 cases (28\%) and Digestive surgery 134 patients with 15 cases $(11.1 \%)$. (table 2$)$.

Table2. Distribution of study population by departments and risk of pressure ulcer

\begin{tabular}{|c|c|c|c|c|}
\hline Hospital & Department & $\begin{array}{l}\text { Number of patients } \\
\text { admitted during the } \\
\text { study period }\end{array}$ & $\begin{array}{l}\text { Number of patients } \\
\text { at risk }\end{array}$ & \begin{tabular}{|l|} 
Number of patients \\
whor developed \\
pressure ulcer
\end{tabular} \\
\hline \multirow[t]{4}{*}{ CHUY } & Internal Medicine & 231 & 81 & 45 \\
\hline & \begin{tabular}{|l|} 
surgery \\
\end{tabular} & 124 & 31 & 11 \\
\hline & Intensive Care Unit & 71 & 35 & 19 \\
\hline & Total & 426 & 147 & 75 \\
\hline \multirow[t]{5}{*}{ HCY } & Cardiology & 168 & 78 & 41 \\
\hline & Neurology & 79 & 40 & 23 \\
\hline & Neurosurgery & 139 & 71 & 39 \\
\hline & Digestive Surgery & 134 & 49 & 15 \\
\hline & Total & 520 & 238 & 118 \\
\hline
\end{tabular}

We divide the patients according to their general presentation in three groups: temporary alteration of consciousness, mobility limitation due to paralysis, multiple co morbidity according to ANAES ( Agence Nationale d'Accreditation et d'Evaluation en Santé )[4]. (Fig 1,2) from this distribution temporary loss of consciousness was the most frequent underlying condition.

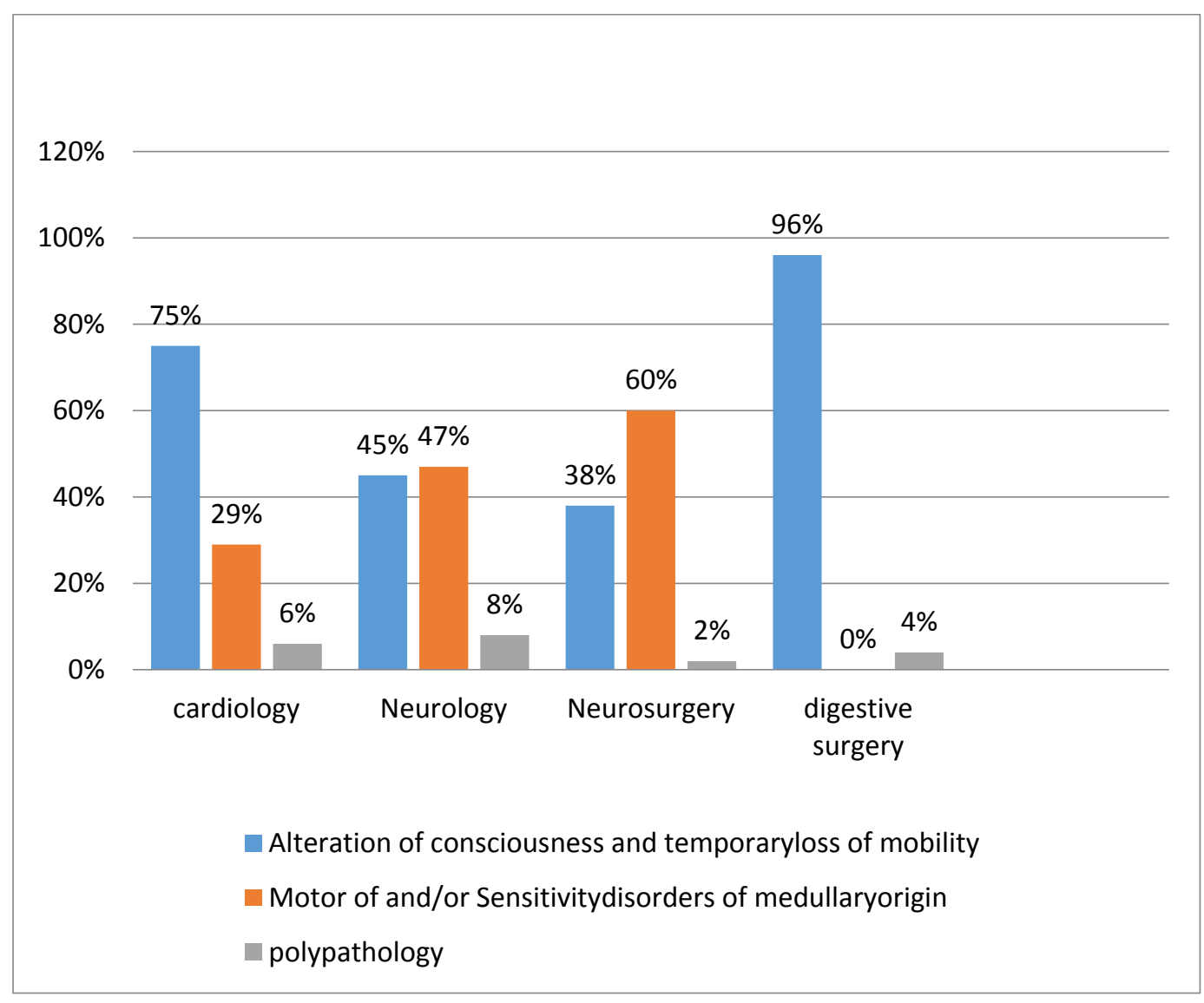

Figure1. Distribution of patients according to the medical underlying condition in HCY departements 
Epidemiology and Therapeutics Aspects of Pressure Ulcers in Two Sub-Sahara African University Teaching Hospitals

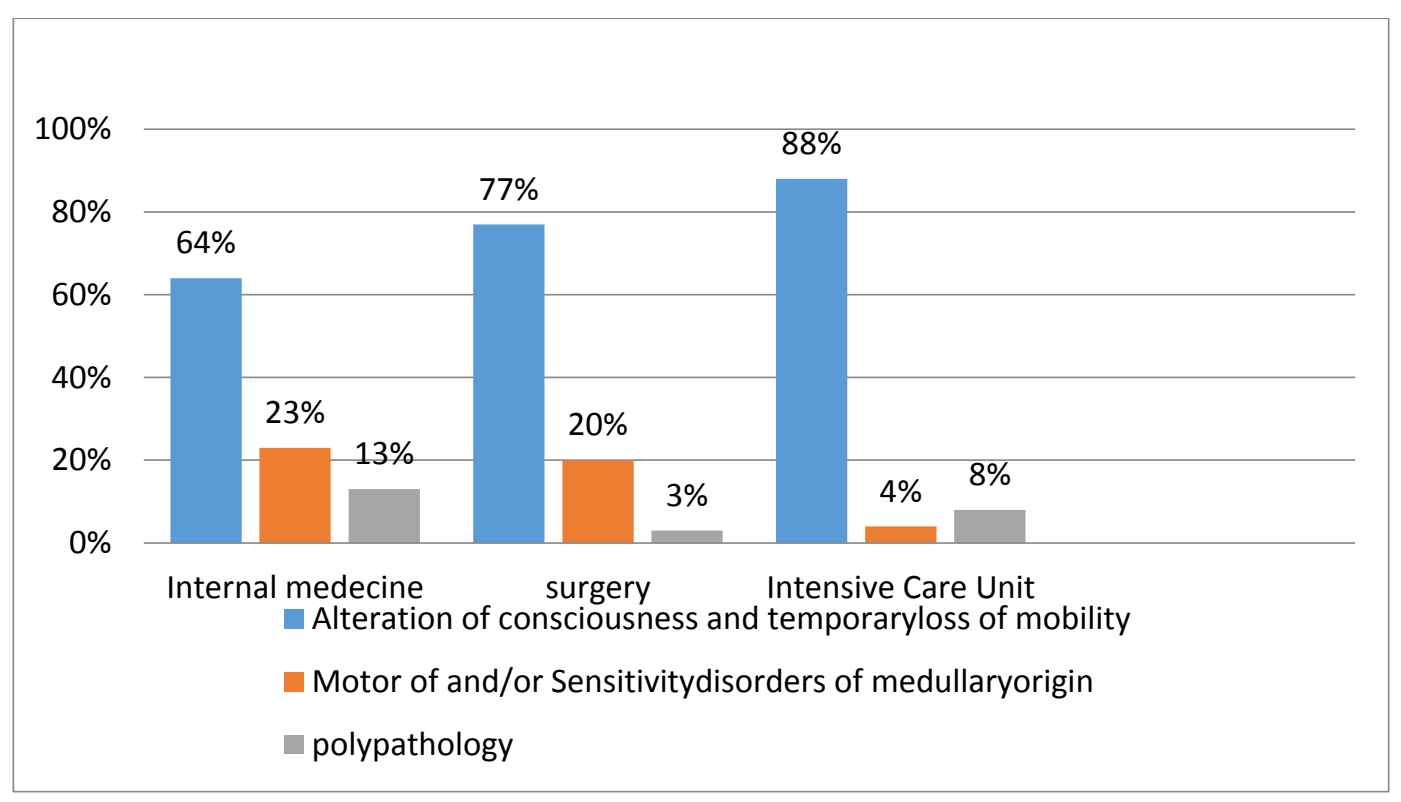

Figure2.Distribution of patients according to medical underlying condition in CHUY

According to WHO performance status which regard the ability of a patient to ambulate and to care about himself, 22 patients with pressure ulcers were classify in category $3(11.4 \%)$ i.e. bedridden or in wheelchair more than $50 \%$ of the time and 171 in category $4(88.6 \%)$ meaning bedridden and unable to care for any need.
Considering the onset of pressure ulcer, $48 \%$ of patients develop pressure ulcers between day 3 and day 6 of hospitalization and $86 \%$ of the Pressure ulcers were present at day 6 before tissue damage progress to the worse stages. (Fig 3)

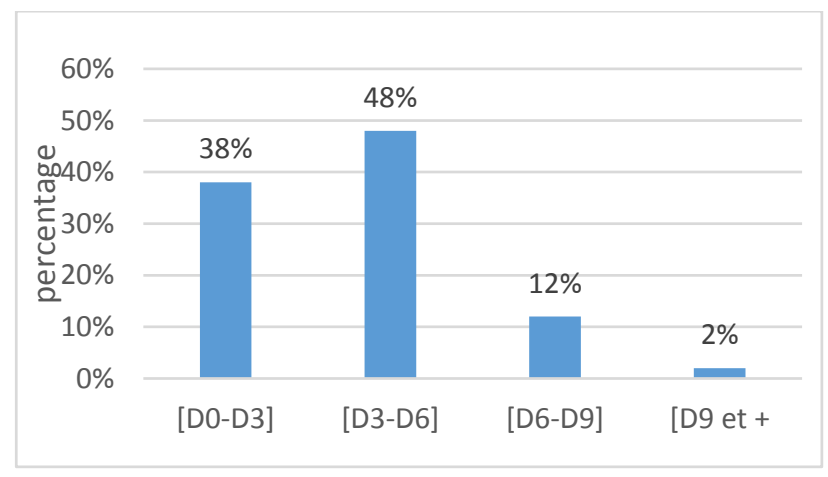

Fig3. Delay of onset of pressure ulcers in daytime interval

The pressure were located mainly on the sacrum follow by ischium and heels. (fig 4)

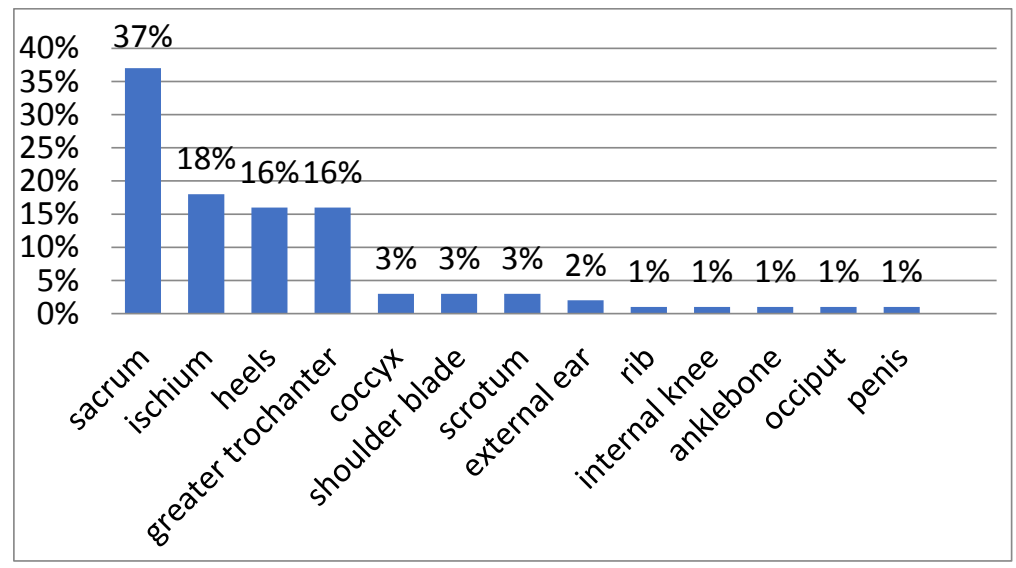

Fig4. Distribution of pressure ulcers in the different anatomic sites 
The predominant locations of the causal pressure were at the sacrum follow by ischium and heels. (fig 4)

Stage 2 ulcers were the most prevalent with $57.4 \%$ follow by stage 1 (30.9\%)

Patients with ulcers were sort according to the evaluation of their bed and in 188 cases out of 193 pressure ulcers; we found the hospital bed inappropriate (beds without neither preventive nor curative properties).

On the basis of our predefined eligibility criteria for surgical management of pressures ulcers, only one (9\%) case of pressure sores was close surgically out of 11 that were follow in the surgical unit in CHU Yaoundé. We use a V-Y Flap to covert Sacral pressure sore in a young polytraumatized patient with bilateral tibial fractures and traumatic brain injury that has a prolonged comatose state for which he was managed in intensive care unit (fig 5).

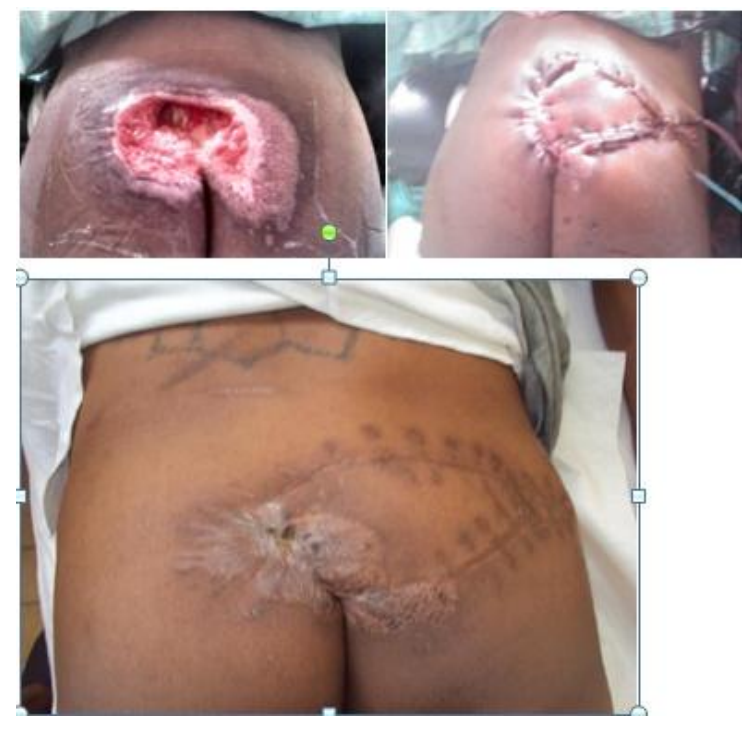

Fig5. Patient treated surgically with a $V$-Y flap

\section{DISCUSSION}

The cumulative incidence in this study is $20 \%$. In CHU it was $17.6 \%$ and $22.7 \%$ in Yaoundé Central Hospital. A relatively high incidence but that falls in a generally recognized range of 0.4 to $38 \%$ [9][3][6]. This high incidence can also be due to increase frequency of stage 1 pressure ulcers with a diagnosis that can be diversely appreciated by confounding factors, given this previous studies focused only on stage 2 pressure ulcer [2]. Surprisingly, there were no difference in the incidence of pressure ulcers between the various specialized units of the two aforementioned hospitals. In general it was postulated that since immobility and paraesthesis are the most contributing factors to the occurrence of pressure sores, the incidence was expected to be greater in neurosurgery from bedridden paraplegic patients [10][5]. But this hypothesis is contradictory to the findings of the present study. Considering that almost $88.6 \%$ of our patients had WHO performance status of grade 4, we can deduce that the burden of medical comorbidities was heavier than that inflicted by trauma in our sample.

Pressure ulcers in this sample arose between day 3 and day 6 of hospitalization. This seem too early compared to reports from Germany were the delay for pressure ulcer onset following hospital admission was 2 weeks in acute care settings and 3 months in nursing homes [9][11]. This early onset of pressure ulcers in our cohort, may point to the impact of nursing care in our health care institution. It is universally recognized that the prevalence of pressure sores is a good indicator of the quality of care of a health facility. In studying the cumulative incidence rather than point prevalence we aimed at assessing the patient - health care system interaction to study how it influences the occurrence of pressure ulcer in our hospital [2]. Our results may imply a deficient nursing care in our tertiary hospital, which needs urgent attention. Previous studies combined point prevalence assessment with the Knowledge, attitude and practice of nursing teams [11]. Because of limited resources these aspects were not study. The presence of a family member to assist in nursing care was assessed by Adegoke et al in Nigeria and they concluded that there was no positive influence of the presence of patient's relatives on the prevalence of pressure ulcer this seems true only if the essential nursing care are provide with enough staff [2].

Pressure is one recognize extrinsic factor in developing ulcers. In the medical nomenclature hospital beds and supports are classified depending on their ability in handling pressure at the interface with the patient's body: type 1 supports with static pressures; type 2 and type 3 supports with dynamic interface pressure and variable component in the structure of mattress [12]. In general our patients had inappropriate beds that increased the risk of pressure ulcer and compromise treatment initiatives [13][12].

In the surgical unit of $\mathrm{CHU}$, we followed-up the general rule that patients with underlying diseases which may be treated or controlled are 
eligible for the surgical closure of pressure ulcer. Patients with terminal diseases, recurrent ulcers, and poor psychological condition might not be considered for surgical treatment [5][8] . Only one patients out of $11(9 \%)$ was fit for surgery and had a favorable postoperative outcome. This relatively small rate of surgical cases compared to the overall burden of pressure ulcer cases requires other therapeutic means to be put in place with the goal to prevent progression of ulceration to osteomyelitis, to reduce fluid and protein loss through the wound, to reduce the risk of malignant ulcer transformation and to improve patient's function and hygiene. This may also be the reluctance to use flaps with their recognize complications of wound dehiscence $31.2 \%$, pressure ulcer recurrence $28.6 \%$ etc [8][10]

Vacuum assisted closure of wounds has recently been described to yield satisfactory results [14][15][16]. This therapeutic modality can be the next gold standard practice especially in stage 3 and 4 pressure ulcers in patients with poor medical condition. Its use in our clinical practice is still hampered by financial cost and lack of clinical expertise. We believe this treatment coupled with an improved nursing care, psychological and nutritional support of patients may be the way forward to the burden of pressure ulcers in our setting [17]. It must also be recognize that more attention should be put on personnel in training to raise their attention on their input in curving down this silent endemic hospital problem especially in low resource setting and to promote the use of score to assess patients at their admission in high risk units like ICU [18].

\section{CONCLUSION}

Pressure ulcers are still a nightmare to health personnel particularly those managing geriatric patients with bed-ridden pathologies like trauma, cerebrovascular accident, HIV or, malignancies. Although surgery can provide favorable therapeutic outcomes through plastic management using flaps, the spectrum of recurrence of pressure ulcers coupled with financial constraints, altered nutritional status with poor ulcer healing potentials, infections or several associated metabolic conditions mandate an individualized patient approach. Our study identify poor nursing care as a capital factor that can be improved in our hospitals, but also highlighted that satisfactory management needs some anticipation by acquisition of a fix ratio of type 2 or 3 bed supports since there is a known prevalence of pressure ulcer that is specific of the main pathologies in each medical specialty and implementation of modern care as Vacuum assisted closure of wounds.

\section{DEClaRATIONS}

Ethics and Consent to Participate: The Ethics committee of the FMSP (faculty of medicine and pharmaceutical sciences) of university of Douala Cameroun approved the realization of this study.

Consent for Publication: All the patients or their legal representative gave their informed consent before getting enroll in the study.

Availability of Data and Material: All data generated or analysed during this study are Included in this published article.

Authors Contributions: Guifo ML, Essomba AG, Djiodoung, Bwelle MG design the study and collect the data. Vuagnat H, Sosso MA read and approved the protocol. All the authors critically revised and approved the final version of the manuscript.

Acknowledgement: We sincerely thank the staff of the CHU of Yaoundé and HCY of Yaoundé for their collaboration.

\section{REFERENCES}

[1] European Pressure Ulcer Advisory Panel and National Pressure Ulcer Advisory Panel Treatment of pressure Ulcers: Quick Reference Guide. Washington DC National Pressure Advisory Panel. www.epuap.org

[2] Adegoke BOA, Odole AC, Akindele LO et al (2013). Pressure ulcer prevalence among hospitalized adults in university hospitals in South West Nigeria. Wound Practice and Research, 21,3, 128-134. Volume 21 Number 3 September 2013

[3] Schiffman J, Golinko MS, Yan A et al (2009) Operative debridement of Pressure Ulcers. World J Surg 33: 1396 - 1402

[4] Dondelinger R, Hamon Mekki F, Meaume S. Prise en charge des escarres (2005) Masson, Plaies et Cicatrisations, Masson Paris : 172-180

[5] Nangole FW, Khainga SO, Kiboi J (2009). Pressure ulcers presentation and Management at Kenyatta National Hospital and Spinal Injury Hospital. East African Medical Journal, 86,545550

[6] Manjeet Singh D, Anurag Ambroz S, Manpreet $K$ et al (2015). Prevalence and clinical evaluation of pressure ulcers using Braden scale from orthopaedic ward of a tertiary care teaching hospital. IAIM 2(3)21-27 
[7] Hong-Lin C, Yin-juan C, Wei Zhang et al(2017). Braden scale (ALB) for assessing Pressure Ulcer Risk in Hospital Patients: A validity and reliability study. Applied Nusing Rsearch. 33, 169-174 H.-L. Chen et al. / Applied Nursing Research 33 (2017) 169-174

[8] Giaquinto-Cilliers MGC, Kotzé J (2014). Pressure ulcers surgical intervention. Wound Healing Southern Africa 2014; 7 (2) 45-52.

[9] Lahmann AN, Halfens RJG, Dassen T (2006). Pressure Ulcers in German nursing homes and acute care hospitals. Prevalence, frequency, and ulcer characteristics. Ostomy/Wound Management, 52(2):20-33

[10] Bamba R, Madden JJ, Hoffman AN (2017). Flaps reconstruction for pressure Ulcers an outcomes analysis. Reconstr Surg Glob Open 2017;5: e1187, published online 18 January 2017.

[11] Awwal Ladan M, Ngaski Garba S, Khalid Sani D et al (2014). Pressure Ulcer Stages among Bed-Ridden Patients in Ahmadu Bello University Teaching Hospital (ABUTH), ZariaNigeria. Journal of nursing and health sciences, e-ISSN: 2320-1959. P-ISSN: 2320-1940 volume 3, Issue 1; PP 61-68.
[12] Rochet JM, Meaume S. Supports d'aide à la prévention et au traitement des escarres (2005) Masson, Plaies et Cicatrisations, Masson Paris : 247-256.

[13] Brown S, Smith I, Brown JM et al (2016). Pressure Relieving Support Surfaces: a randomized Evaluation 2 (PRESSURE 2) Study protocol for a randomized controlled trial. Biomed Central (2016), 17, 604

[14] Mulimba JAO (2016). Wound care in orthopaedic. EAOJ; 10,39-40.

[15] Border KW, Nguyen B, Bodor RM (2016). Negative pressure wound therapy with instillation in a chronic Non-healing Right hip trochanteric pressure ulcer. Cureus 8(11):e877

[16] Tréssallet C, Royer B, Menegaux F (2009) la cicatrisation dirigée par pression négative dans les pertes de substance musculocutanées étendues: principes et techniques. Jchir186 : 281-284

[17] Vijay L, Prem SB, Salyamoorthy R et al (2015). Negative pressure wound therapy as an adjunct in healing of chronic wounds. IWJ,volume 12, issue 4, 436-442.

[18] Bluestein D, Javaheri A. Pressure ulcers: Prevention, Evaluation, and Management. Am Fam Physician. 78(10): 1186-1194, 1195-1196.

Citation : Guifo Marc Leroy, Essomba Arthur Georges, Djiodoung Zoko Serge, Bwelle Motto Georges, Vuagnat Hubert, Sosso Maurice Aurelien, Epidemiology and Therapeutics Aspects of Pressure Ulcers in Two Sub-Sahara African University Teaching Hospitals. ARC Journal of Surgery.2018 ;4(2) : 1-7. doi: dx.doi.org/ 10.20431/2455572X. 0402001.

Copyright: (C) 2018 Authors. This is an open-access article distributed under the terms of the Creative Commons Attribution License, which permits unrestricted use, distribution, and reproduction in any medium, provided the original author and source are credited. 